\title{
Políticas de escala e planejamento regional: o Plano de Ação da Macrometrópole Paulista e a Região Metropolitana do Vale do Paraíba e Litoral Norte
}

\author{
Rosa Scaquetti \\ Pedro Ribeiro-Moreira
}

\begin{abstract}
Resumo
As transformações recentes do capitalismo no contexto do processo de neoliberalização do espaço têm implicações sobre a governança regional e metropolitana. Nesse contexto, há um reescalonamento do território e novas regiões de planejamento são criadas, como a Macrometrópole Paulista e a Região Metropolitana do Vale do Paraíba e Litoral Norte, no estado de São Paulo. Este artigo tem o objetivo de discutir limites, potencialidades e implicações da agenda de planejamento nessas imbricadas escalas, com evidência sobre o Plano de Ação da Macrometrópole Paulista, confrontado com diretrizes do planejamento regional em experiências anteriores, notícias da mídia e dados de entrevistas amparados em pesquisa bibliográfica e considerados os critérios de escolha de projetos e interesses que influenciam sua governança. Espera-se que este estudo contribua para o desafio de avançar uma agenda de planejamento mais coerente com as questões macrometropolitanas no quadro do planejamento regional brasileiro.
\end{abstract}

Palavras-chave | Planejamento regional; Plano de Ação da Macrometrópole Paulista; políticas de escala; Região Metropolitana do Vale do Paraíba e Litoral Norte.

Classificação JEL | O21 R52 R58

Scale policies and regional planning: the Action Plan of the Macrometropolis Paulista and the Metropolitan Region of the Paraíba Valley and North Coast

\begin{abstract}
The recent transformations of capitalism in the context of the neoliberalization process of the space produced implications for regional and metropolitan governance. In this context, there
\end{abstract}


is a rescheduling of territory and new planning regions are created, such as the Macrometropolis of São Paulo and the Metropolitan Region of Vale do Paraíba and North Cost (Litoral Norte), in the state of São Paulo, Brazil. This article aims to discuss the limits, potentialities and implications of the planning agenda in these imbricated scales with evidence on the Macrometrópole Action Plan - PAM confronted with previous experiences of regional planning guidelines, media news and data from interviews supported by bibliographic research considering the criteria for choosing projects and interests that influence governance. This study is expected to contribute to the challenge of moving towards a more coherent regional agenda for macro-metropolitan issues within the framework of Brazilian regional planning.

Keywords | Action Plan of the Macrometropolis Paulista; regional planning; scale policies; the Metropolitan Region of the Paraíba Valley and North Coast.

JEL Classification | O21 R52 R58

\section{Políticas de escala y planificación regional: el Plan de Acción de la Macrometrópolis Paulista y la Región Metropolitana del Vale do Paraíba y Litoral Norte}

\section{Resumen}

Las recientes transformaciones del capitalismo en el contexto del proceso de neoliberalización del espacio han producido consecuencias para la gobernanza regional y metropolitana. En este contexto, hay una reprogramación del territorio y se crean nuevas regiones de planificación, como la Macrometropolis de São Paulo y la Región Metropolitana del Vale do Paraíba y Litoral Norte, en el estado de São Paulo. Este artículo tiene como objetivo examinar los límites, potencialidades e implicaciones del programa de planificación en estas escalas imbricadas, con pruebas sobre el Plan de Acción de la Macrometrópolis Paulista, confrontado con directrices de planificación regional en experiencias anteriores, noticias de los medios de comunicación y datos de entrevistas apoyadas por la investigación bibliográfica y considerados los criterios de selección de proyectos e intereses que influyen en su gobernanza. Se espera que este estudio contribuya al reto de avanzar hacia un programa de planificación regional más coherente con las cuestiones macro-metropolitanas dentro del marco de planificación regional brasilero.

Palabras clave | Planificación regional; Plan de Acción de la Macrometrópolis Paulista; políticas de escala; Región Metropolitana del Vale do Paraíba y Litoral Norte.

Clasificación JEL | O21 R52 R58

\section{Introdução}

O presente artigo aborda a maneira como, a partir da perspectiva do processo de urbanização em curso, a reestruturação na economia, na política e na própria sociedade geraram a reestruturação das escalas políticas de planejamento e, consequentemente, uma série de desafios e oportunidades para o planejamento regional metropolitano. Deste ponto, busca uma possível crítica aos arranjos 
institucionais e ações de planejamento, procurando contribuir com as iniciativas de investigação acerca da integração do território e desenvolvimento regional no contexto da Macrometrópole Paulista (MMP).

O processo de urbanização contemporâneo, em que a cidade é a expressão espacial da ocupação humana desde a industrialização, acirrou-se a partir de 2008 quando mais da metade da população global, apesar de se concentrar em apenas em 3\% do território mundial, passou a viver nas cidades. Segundo a Organização das Nações Unidas (ONU), as cidades que mais cresceram foram aquelas que têm mais de 500 mil habitantes. Em outras palavras, "sobra" na divisão territorial do planeta um enorme espaço "não urbano" onde outrora se concentravam quase todas as atividades econômicas (BRENNER, 2018).

As transformações ocorridas no tecido urbano, no contexto do capitalismo mundial do final do século XX, com o advento da reestruturação produtiva, o processo de globalização e a nova economia política urbana (SANTOS, 2005) são determinantes que passam a exigir diferentes e novas dinâmicas de organização territorial, acarretando o reescalonamento da governança e gestão do território (BRENNER, 2004, 2010). Historicamente, esses processos se traduzem na emergência de um Estado empreendedor (HARVEY, 2005) e de um regime espacial estatal competitivo que trazem consigo uma tendência inegável ao agravamento das questões socioambientais na produção do espaço.

Partindo do pressuposto de que o processo de produção social do espaço se dá sob um modelo de desenvolvimento pós-keynesiano e neoliberal, assumindo a tese de que as escalas espaciais de atuação estatal são reterritorializadas pelo curso do desenvolvimento capitalista, tal contexto coloca as escalas em debate, ou seja, nem a urbanização, nem a acumulação, nem a regulamentação estatal têm como prerrogativa uma escala espacial única, exclusiva e restrita para o desempenho de reversão dos efeitos das crises cíclicas. Dessa forma, os limites geográficos das relações sociais, políticas e econômicas se tornaram objetos diretos de contestação sociopolítica. A escala metropolitana representa, portanto, uma construção política, um campo em que agentes estão em disputa dinâmica constante, em que se (des)constroem as escalas (BRENNER, 2017).

Para se observar a aludida questão da reestruturação das escalas, há de se ter em vista que esta pode ir além das disputas entre as cidades e a competição para ver qual delas recebe mais investimentos para recuperação de empregos na era liberal, ou seja, há necessidade de se fazer a crítica às abordagens que assumem um determinismo do desenvolvimento econômico da governança. Em outras palavras, aqueles que abordam a questão da escala se referindo às questões estritamente econômicas (COX, 2010).

A governança metropolitana enfrenta um grande desafio representado pela necessidade de articular as pressões das sociedades locais dentro do processo de urbanização planetária e os efeitos da urbanização extensiva, direcionada a certo 
conceito de progresso econômico que, contraditoriamente, resulta no aumento também da vulnerabilidade social (MONTE-MÓR, 2006). No entanto, o dilema apresentado no cenário globalizado, quando observado na escala regional metropolitana, apresenta uma dificuldade ainda maior, uma vez que convivem as maiores concentrações de riqueza e de pobreza. Deste modo, as pressões e conflitos recaem diretamente nos governos locais, de quem são cobradas soluções para problemas situados em outras escalas de governo (FREY, 2007) e que se referem diretamente aos conflitos de escala.

O texto busca compreender as particularidades da governança na escala macrometropolitana para desenvolver a análise das perspectivas de ações de planejamento na ainda recente Região Metropolitana do Vale do Paraíba e Litoral Norte (RMVPLN), criada em 2012, no estado de São Paulo. O estudo está centrado no processo da criação e institucionalização dessa região metropolitana, a RMVPLN, situada na Macrometrópole Paulista (MMP) e explora o desenvolvimento desse processo na tentativa de compreender os contornos e potenciais desse arranjo de planejamento regional. Partindo da pressuposição de uma lógica dentro das ações do grupo que propõe originalmente a criação da RMVPLN, lógica essa situada no argumento do fato regional em oposição ao argumento do fato metropolitano, procura-se abarcar como se deu a prática desse grupo de atores diante das condicionalidades históricas da governança do território metropolitano.

Como procedimento metodológico, apresenta-se o recorte espacial, incluindo sua inserção na especificidade dos dados da Macrometrópole Paulista (MMP) e, a partir de uma análise do Plano de Ação da Macrometróple (PAM), por meio da documentação disponibilizada pela Empresa Paulista de Planejamento Metropolitano (EMPLASA), relacionam-se os projetos propostos para o vetor Região Metropolitana do Vale do Paraíba e Litoral Norte, com os dados das análises feitas acerca do processo de criação e institucionalização da mesma. Esse processo se levanta por meio dos dados da revisão bibliográfica, pesquisa documental, entrevistas e notícias da mídia regional, estadual e nacional. Busca-se abordar as particularidades de sua trajetória desde a proposição até sua institucionalização, procurando alçar suas estratégias e interesses ${ }^{1}$. Com isso, espera-se que a análise do Plano de Ação Metropolitano (EMPLASA, 2014), aponte para o desafio de se avançar para uma agenda estadual mais específica das questões macrometropolitanas, para além de transporte/mobilidade, temas mais comuns, incluindo outros tantos, cada vez mais importantes, como meio ambiente e

\footnotetext{
${ }^{1} \mathrm{O}$ presente artigo foi escrito no contexto da realização de uma pesquisa maior e realizado a partir dos resultados parciais obtidos na mesma, em que se estuda a governança da Região Metropolitana do Vale do Paraíba e Litoral Norte (RMVPLN), o processo de sua criação e institucionalização. Essa pesquisa recebeu o Certificado de Apresentação para Apreciação Ética (CAAE) sob o N. 46505115.5.0000.5503.
} 
saneamento, sempre voltados às necessidades da região, contribuindo para melhor equivalência do equilíbrio regional.

Além dessa introdução, o estudo traz uma seção sobre as particularidades do planejamento urbano no Brasil, o histórico da formação teórico-conceitual e normativo do discurso da metrópole, adentrando o processo de urbanização na Macrometrópole Paulista e da construção do discurso sobre a metrópole num contexto em que emergem a reestruturação e o reescalonamento do planejamento regional. Em seguida, uma seção com enfoque no caso da Região Metropolitana do Vale do Paraíba e Litoral Norte, em sua natureza desigual e fragmentada, aborda-se o processo de criação e institucionalização da RMVPLN, fazendo as relações dessa escala de planejamento com as ações presentes na Carteira de Projetos do Plano de Ação da Macrometrópole (PAM), concluindo com uma análise das consequências da forma centralizada de planejamento no território paulista.

\section{O Brasil no discurso da metrópole}

$\mathrm{O}$ aludido contexto de mudanças estruturais aqui tratado acarreta na metamorfose do espaço metropolitano. Com isso, nota-se que as iniciativas de arranjos de planejamento e governança nas metrópoles ao longo do tempo, muitas vezes, ao invés de atenuarem, acabam por acentuar desigualdades e conflitos, sociais, econômicos, políticos ou ambientais (FREY, 2007). As diferentes etapas no processo de estruturação dos arranjos institucionais, principalmente nos aspectos legais, beneficiam institucionalmente a governança metropolitana; por outro lado, demonstram também a ausência de um olhar voltado para a integração entre as escalas, bem como para o padrão de financiamento da governança das metrópoles, a partir de conceitos mais amplos do que a simples disponibilidade de recursos. Ademais, há a fragilidade e, em alguns casos, o esgotamento das estruturas de participação social e a ausência de uma autoridade metropolitana.

A experiência de Planejamento Regional no Brasil, nascida em uma época em que o conceito de desenvolvimento estava diretamente ligado à industrialização e à urbanização, evidencia uma relação de exclusividade com a expressão urbano/metropolitana. É certo que os primeiros conceitos de organização regional no caso brasileiro surgiram a partir de realidades específicas e urbanas conurbações e aglomerações em geral. Este fato conduziu a uma visão seccionada do espaço entre duas formas aparentemente opostas — urbano e rural — em concepção típica do processo de urbanização dos anos 1960 e 1970, quando a industrialização fordista induzia ao êxodo rural, ao inchaço das cidades e outros fenômenos característicos do final da modernidade no Brasil.

As regiões metropolitanas foram oficializadas no país como áreas de planejamento pela edição da Lei Complementar N. 14/1973, no governo de Emílio Garrastazu 
Médici. Seu objetivo era criar unidades administrativas em áreas centrais do país, as principais capitais brasileiras, com o intuito de submeter os conteúdos socioeconômicos do espaço metropolitano às diretrizes centralizadoras e autoritárias do Estado, por meio de um planejamento tecnocrático, como de fato se deu.

Anos depois, a redemocratização do país contribuiu com diversas modificações que interferiram também no processo de planejamento, entre elas na estrutura do poder público no papel do Estado, no relacionamento entre os entes federativos e no desenho das políticas públicas. O resultado foi a delegação de maior autonomia ao poder local, apontando para um processo caracterizado como descentralização. Observa-se, entretanto, que a descentralização não significou melhoria das estruturas e capacidade de governança dos entes subnacionais para exercerem suas atribuições conjugadas em territórios integrados. O reescalonamento do Estado e a redistribuição territorial de poder produziram maior fragmentação espacial, aprofundando a heterogeneidade de estruturas regionais, produtivas, sociais e culturais (BRANDÃO, 2007; LEITÃO, 2009).

Mesmo nesse contexto, houve, nas últimas três décadas, a necessidade de constituição de pactos territoriais e articulação de instâncias de decisão e arranjos horizontais. Contudo, muitas das limitações e distorções da gestão regionalmetropolitana presentes no regime militar continuaram a existir pós-Constituição de 1988. Houve, especialmente, dificuldade de adaptação ao novo formato federativo com relação à construção de relações intra e inter-regional, caracterizando a atual crise federativa em que vivemos (TAVARES, 2018; LEITÃO, 2009).

Outro aspecto importante a se destacar, acerca do contexto brasileiro, é que, diferentemente dos países da denominada economia central, aqui não houve a experiência do estado de "bem-estar social", com o Estado interferindo diretamente no processo de produção e distribuição da riqueza com o objetivo de regular e dinamizar a economia e ampliar a abrangência das políticas sociais.

No Brasil, o Estado foi historicamente "patrimonialista", também não houve uma revolução industrial nos moldes "clássicos" no país. Com isso, o acesso ao consumo se limitou historicamente a poucos brasileiros, caracterizando uma espécie de fordismo incompleto e periférico (LIPIETZ, 1988). Diferentemente dos países centrais, o Estado brasileiro atuou de forma a beneficiar quem dele se apropriava (OLIVEIRA, 2003), perpetuando a histórica desigualdade social e de concentração do poder econômico.

Com a transição para a redemocratização e o processo de elaboração da Constituição Federal de 1988, surge a necessidade de novos rumos para a governança metropolitana. No entanto, por força da hegemonia ainda presente nas representações parlamentares, pouco se altera das condições político-estruturais que mantêm o poder concentrado em oligopólios e nas tradicionais elites nacionais. 
Separado por várias décadas daquele momento inicial da experiência de Planejamento Regional no Brasil, o próprio Estatuto da Cidade, de 2001, em seu título "Da Cidade", denuncia a permanência deste comprometimento. Apesar de definir como objeto do Plano Diretor, o "conjunto do município", esta inserção se torna mera formalidade. Na medida em que obriga a definição do perímetro urbano, cria uma zona de inclusão no interior da qual serão desenvolvidos os instrumentos constitucionais do Estatuto da Cidade, enquanto o espaço externo ao, além desse perímetro, permanece excluído das possibilidades de intervenções de planejamento que ultrapassem as delimitações do macrozoneamento, inclusive a própria competência do ente municipal.

Depois de um longo processo, em 12 de janeiro de 2015, entrou em vigor a Lei Federal número 13.089, referente ao denominado Estatuto da Metrópole, instrumento jurídico que estabelece as diretrizes gerais para o planejamento, a gestão e a execução das Funções Públicas de Interesse Comum, em regiões metropolitanas e em aglomerações urbanas instituídas pelos estados, as normas referentes ao Plano de Desenvolvimento Urbano Integrado (PDUI) e outros instrumentos de governança interfederativa, além dos critérios para o apoio da União às ações que envolvam o desenvolvimento urbano.

Por metrópole, o estatuto estabelece que esta representa o espaço urbano com continuidade territorial e, em razão de sua população e relevância política e socioeconômica, tenha influência nacional ou sobre uma região que configure, no mínimo, a área de uma capital regional, fornecendo bens e serviços à região, abrangendo produtos industriais, educação, saúde, serviços bancários, comércio, empregos e outros itens pertinentes. Por fim, a lei caracteriza como região metropolitana a aglomeração urbana que configure uma metrópole.

A existência do PDUI configura condição sine qua non para que a União preste apoio às ações de desenvolvimento urbano integrado (Capítulo V), com realce para as iniciativas dos estados e dos municípios voltadas à governança interfederativa (art. 13). Nesse caso, será garantido que a unidade territorial urbana possua gestão plena, nos termos da lei, que pressupõe: a) formalização e delimitação mediante lei complementar estadual; b) estrutura de governança interfederativa própria; e c) plano de desenvolvimento urbano integrado aprovado (art. 2, III) (MOURA; HOSHINO, s/d, p. 9).

Nos termos da Lei Federal, governança interfederativa se refere à incorporação, ao desmembramento e fusão de municípios, à formalização de regiões metropolitanas, microrregiões e aglomerações urbanas por seus municípios limítrofes, integrando a organização, o planejamento e a execução das funções públicas de interesse comum (FPICs).

A legislação brasileira definiu a atribuição do planejamento regional às Constituições estaduais. Desse modo, as regiões metropolitanas paulistas são geridas pela Casa Civil do Estado, que, por sua vez, instituiu a Subsecretaria de Desenvolvimento 
Metropolitano, que, contava com o apoio técnico da Empresa Paulista de Planejamento Metropolitano (EMPLASA), até sua extinção pelo atual governo, em 2019.

\section{Definição das fronteiras e construção discursiva da MMP}

A Macrometrópole Paulista foi pela primeira vez tratada como macrometrópole pelo sociólogo Vilmar Faria (1981), que usa a metodologia das cidades hierarquizadas para sua análise da região. Posteriormente, Lencioni (2003 e 2004) estuda a Macrometrópole Paulista a partir da visão de cidade-região global e se refere a ela como "nó essencial na economia internacional" (LENCIONI, 2017). Em ambos os estudos predominam os referenciais de um processo regionalizado de urbanização que se consolida pela reestruturação produtiva e a globalização, em boa parte orientadora da metropolização do território paulista.

Segundo Lencioni (2004), as transformações no sistema produtivo e nas dinâmicas do território industrial, marcadamente após os anos 1970, refletem-se também no estado de São Paulo. A autora fala da regionalização do espaço urbano a partir da capital, São Paulo, e discute a teoria da polarização espacial, dizendo que na hierarquia urbana a capital está em primeiro lugar e atua como um polo nacional. Contudo, com a reestruturação produtiva e a relação não dicotômica entre capital e interior do estado, ocorre a definição do que ela chama de uma nova regionalização, por meio da qual classifica como espaços metropolizados e espaços não metropolizados do interior (metrópole expandida), o entorno metropolitano, o litoral e trechos da própria região metropolitana de São Paulo.

$\mathrm{Na}$ síntese de Tavares (2018), a conceituação variada da MMP aponta para uma construção dialética, "inclusive na sua conceituação". Essa foi, segundo o autor, sendo incorporada pelas ações de planejamento, onde se tem como resultado do processo a transformação da MMP em uma "região de planejamento".

Considerando as construções teórico-conceituais do novo regionalismo e as fragilidades da institucionalização das metrópoles brasileiras, Leonel, Zioni e Momm (2019) alegam que "a MMP pode ser entendida como um território dos mais dinâmicos processos da urbanização contemporânea" (LEONEL; ZIONI; MOMM, 2019, p. 2). Destarte a compreensão das dinâmicas de urbanização do território, as autoras questionam qual o perímetro da macrometrópole e avançam no sentido de demonstrar a diversidade do que denominaram de nova escala de governança e planejamento.

Esse processo de mais de 30 anos de estudos e pesquisa consolidou, segundo Tavares (2018), a MMP como território de planejamento e de ações. Como limites, o autor aponta para a não superação da divisão setorizada das ações administrativas, somada à fragilidade orçamentária e burocrática, representada tanto pelas reformas 
na estrutura de gestão, que recentemente rebaixaram a posição da Secretaria de Desenvolvimento Metropolitano, criada em 2011, transformando-a em subsecretaria da Casa Civil. Bem como pelos cortes de recursos orçamentários, com reflexos no Plano Plurianual PPA 2016/2019, onde nada além de 1\% da sua previsão total foi destinada para a Carteira de Projetos do Plano de Ação da Macrometrópole - 2012/2040.

O estado de São Paulo, via de regra, enfrenta grandes desafios, tais como os relativos ao saneamento, ao abastecimento de água e à habitação. Quando se trata da questão da governança desse cenário, no contexto do Estatuto da Metrópole, deixa a desejar. A relação do governo do estado de São Paulo com o planejamento regional metropolitano, após o advento do Estatuto da Metrópole e a criação da Macrometróple Paulista, é analisada, entre outros, no estudo de Castro e Santos Júnior (2017), em síntese:

O plano legal-normativo metropolitano, de acordo com o que foi aprovado [em 2015], está deslocado do plano real-prático da vida cotidiana e do próprio histórico de planejamento e execução de políticas públicas de caráter metropolitano do governo paulista, que sempre exerceu grande poder centralizador e de tutela sobre as políticas territoriais sobre seu território estadual, sem, no entanto, promover a sinergia necessária para a ação cooperada entre diferentes atores, tanto públicos como privados, com diferentes graus de autonomia e poder de intervir na agenda pública. (CASTRO; SANTOS JUNIOR, 2017, p. 717).

Causa certa estranheza que o Estatuto da Metrópole (Lei N. 13.089, de 12/01/2015) não faça menção às macrometrópoles e ao seu principal instrumento de gestão, o Plano Diretor Urbano Integrado (PDUI). Apesar de ser uma forma de colocar em perspectiva regional as Funções Públicas de Interesse Comum (FPICs) das regiões metropolitanas, não fala de integração entre as mesmas, que, no caso da MMP, são estruturalmente interligadas. Sobre a necessidade de conectar os planejamentos entra as RMs, Tavares diz haver "pouca correspondência das partes em relação ao todo" e completa: “(...) parece haver um descolamento entre o debate e a gestão em relação ao seu reconhecimento" (TAVARES, 2018, p. 129).

$\mathrm{Na}$ esteira da legislação brasileira, no que se refere ao planejamento regional, percebe-se, portanto, determinadas omissões que não podem ser explicadas apenas pela superficialidade das discussões, quando os fatos já eram há muito conhecidos. Se o Estatuto da Cidade silenciou sobre as possibilidades de interação entre os conceitos de urbano e rural, desta vez, com o Estatuto da Metrópole, o silêncio está no vácuo das demais formações metropolitanas, nelas incluídas as macrometrópoles. 


\section{Planejamento regional no processo de urbanização na Macrometrópole Paulista}

A urbanização do território da Macrometrópole Paulista (MMP) se deu em um processo em que o parque industrial concentrado inicialmente em torno da capital de São Paulo espraia-se para o interior, ação mobilizada pelas políticas de planejamento, configurando um processo de reterritorialização das forças produtivas, provocado pelo estado por meio de planos e ações de planejamento (TAVARES, 2018).

A moderna urbanização da hoje considerada Macrometrópole Paulista tem início na década de 1950 e se intensifica nos anos 1970, durante o ciclo conhecido como "milagre brasileiro". Este foi um período marcado pela centralização do poder no país, nas mãos do executivo nacional, que acabou sendo impactado pela chamada Crise do Petróleo, a partir de 1974, de profundas implicações na economia mundial e expressivos reflexos no Brasil.

As mudanças ocorridas no país a partir da chamada transição democrática, entre 1978 e 1989, tiveram como marca a descentralização da atuação do Estado Nacional e a abertura econômica, com a flexibilização de algumas medidas de proteção do mercado nacional. Devido ao contexto de crise internacional, com a quebra do acordo de Bretton Woods e a entrada na era da acumulação flexível (HARVEY, 2014), os países considerados subdesenvolvidos, entre eles o Brasil, ficaram sujeitos aos desígnios das agências de fomento, acatando o que veio a ser chamado de Consenso de Washington. Ao mesmo tempo, com a desregulação econômica, iniciou-se um processo de guerra fiscal e competitividade entre as diferentes escalas de atuação do Estado, na busca de novos investidores para suas regiões. (FIORI, 1995; FERNANDES, 2001).

Com o avanço do processo de interiorização ocorreu a formação de uma pluralidade de regiões metropolitanas no entorno da capital paulista, e a MMP se constitui como uma cidade-região global (LENCIONI, 2015). Segundo Gomes, Reschilian e Uehara (2018), uma experiência bem-sucedida de planejamento regional no estado de São Paulo, a Política de Desenvolvimento Urbano e Regional, de 1976, desenvolveu proposições para os seguintes programas governamentais de âmbito regional: Cidades Médias, Macro-eixo Rio-São Paulo, Macrometrópole, Desconcentração e Descentralização Industrial e Cidades Pequenas (SECRECRARIA DE ECONOMIA E PLANEJAMENTO, 1978).

As diretrizes refletidas por esses programas vinham de diversos planos e estudos regionais, produzidos nos anos 1970, no contexto do II Plano Nacional de Desenvolvimento, todos no sentido de coordenar o investimento e a regulamentação do uso do solo; conter o aumento ainda maior da concentração na metrópole; e descentralizar a produção para centros de médio porte (GOMES; RESCHILIAN; UEHARA, 2018, p. 159). Portanto, na sua origem, a MMP tem no 
processo de interiorização industrial e administrativa o desenvolvimento da urbanização em que viria a dar conformação à área mais urbanizada do país.

O complexo chamado de Macrometrópole Paulista é composto pela Região Metropolitana de São Paulo; Região Metropolitana da Baixada Santista; Região Metropolitana de Campinas; Região Metropolitana do Vale do Paraíba e Litoral Norte; Região Metropolitana de Sorocaba; Aglomeração Urbana de Jundiaí; Aglomeração Urbana de Piracicaba e Unidade Regional Bragantina. A MMP possui um total de 174 municípios, distribuídos em um raio de 200 quilômetros da capital, apresentando uma taxa de urbanização de cerca de 94,83\% (EMPLASA, 2019). A população total é de 33.652.991, sendo que desses, 2,68 milhões de habitantes viviam em assentamentos precários, em 2016 (Tabela 1).

\section{Tabela 1 - Dados comparativos da Macrometrópole Paulista}

\begin{tabular}{lccccc} 
Indicadores & MMP (A) & São Paulo (B) & Brasil (C) & $\begin{array}{c}(\mathrm{A}) /(\mathrm{B}) \\
\mathrm{em} \%\end{array}$ & $\begin{array}{c}(\mathrm{A}) /(\mathrm{C}) \\
\mathrm{em} \%\end{array}$ \\
\hline Área $\left(\mathrm{km}^{2}\right)$ & 53,40 & 248,21 & $8.516,00$ & 21,50 & 0,60 \\
PIB [R\$] 2016 & $1.669 .448 .647,00$ & $2.038 .004 .931,00$ & $6.267 .000 .000,00$ & 81,90 & 26,64 \\
População 2018 & 33.652 .991 & 45.094 .866 & 209.469 .320 & 74,63 & 16,07 \\
\hline
\end{tabular}

Fonte: Elaboração dos autores a partir de dados IBGE (2020) e EMPLASA (2020).

Seja em extensão territorial, população envolvida e produção econômica, este conjunto urbano constitui o complexo que conduz São Paulo e a MMP ao papel de "cidade global", um conceito polêmico e alvo de críticas (FERREIRA, 2003). Sua posição e papéis no mundo globalizado podem ajudar a compreender a inserção da RMVPLN na Macrometrópole Paulista (ver Figura 1).

Com o intuito de orientar o desenvolvimento da Macro Metrópole Paulista MMP, o governo do Estado de São Paulo, por meio da EMPLASA, propôs o Plano de Ação da Macrometrópole (PAM) - 2020/2040, desenvolvido entre os anos de 2013 e 2014. O PAM definia algumas diretrizes gerais, quais sejam: criar um processo permanente de integração dos diferentes setores administrativos; valorizar as funções estruturadoras da Macrometrópole Paulista (mobilidade e logística, saneamento ambiental e habitação) integrando setorial e institucionalmente os projetos e as ações. Por fim, determinar os parâmetros da Política de Desenvolvimento da Macrometrópole Paulista pela fixação de uma carteira de projetos e investimentos (TAVARES, 2016). 
Figura 1 - Região Metropolitana do Vale do Paraíba e Litoral Norte na Macrometrópole Paulista

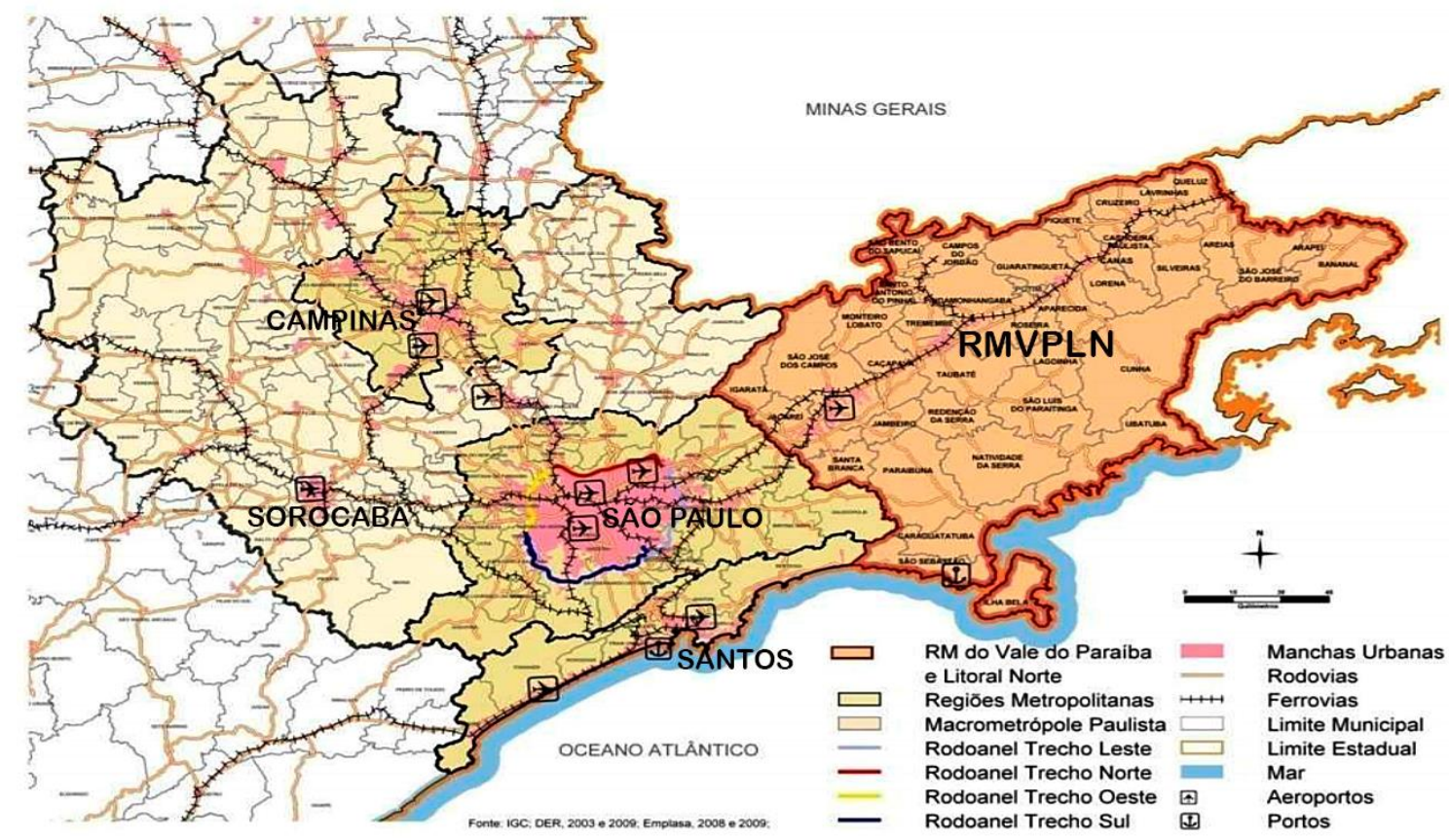

Fonte: Acréscimos dos autores sobre base da EMPLASA, 2011 (Anterior à criação da R. M. de Sorocaba).

Conceitualmente, o PAM propunha a constituição de uma Macrometrópole "una", "diversa", "policêntrica", "compacta" e "viva" (EMPLASA, 2014a, p. 11). Criticamente, citando Negreiros, Santos e Miranda (2015), Leonel, Zioni e Momm (2019) destacam a maneira com que essa carteira de projetos está embasada em uma concepção de planejamento voltada para o desenvolvimento econômico de interesse empresarial.

Foram definidos eixos conceituais e vetores de desenvolvimento, sendo esses eixos, basicamente, conectividade territorial e competitividade econômica; coesão territorial e urbanização inclusiva; além de governança metropolitana. Ao analisar o Plano de Ação da Macrometrópole, é possível notar que cada uma das Regiões Metropolitanas do Estado de São Paulo envolvidas no processo constituía um vetor territorial de desenvolvimento específico. Também o rol de intervenções e os montantes de recursos eram distribuídos pelos eixos considerando os vetores existentes.

Constam dos estudos da EMPLASA (2014a; 2014b) que tais vetores foram eleitos com a finalidade de dar melhores condições de dinamismo e restabelecimento das relações físicas e funcionais das áreas da MMP. Estas apresentavam, na prática, uma proposta de intensificação das ligações entre as seis regiões delimitadas pela influência de algum eixo rodoviário de responsabilidade estadual. Com capacidade para serem ocupados por novas atividades urbanas e possibilidades de aumento de 
fluidez no trânsito, tais vetores deveriam se localizar em um raio aproximado de cem quilômetros da capital (ver Figura 2).

\section{Figura 2 - Vetores Territoriais da MMP - Vetor de Desenvolvimento Perimetral}

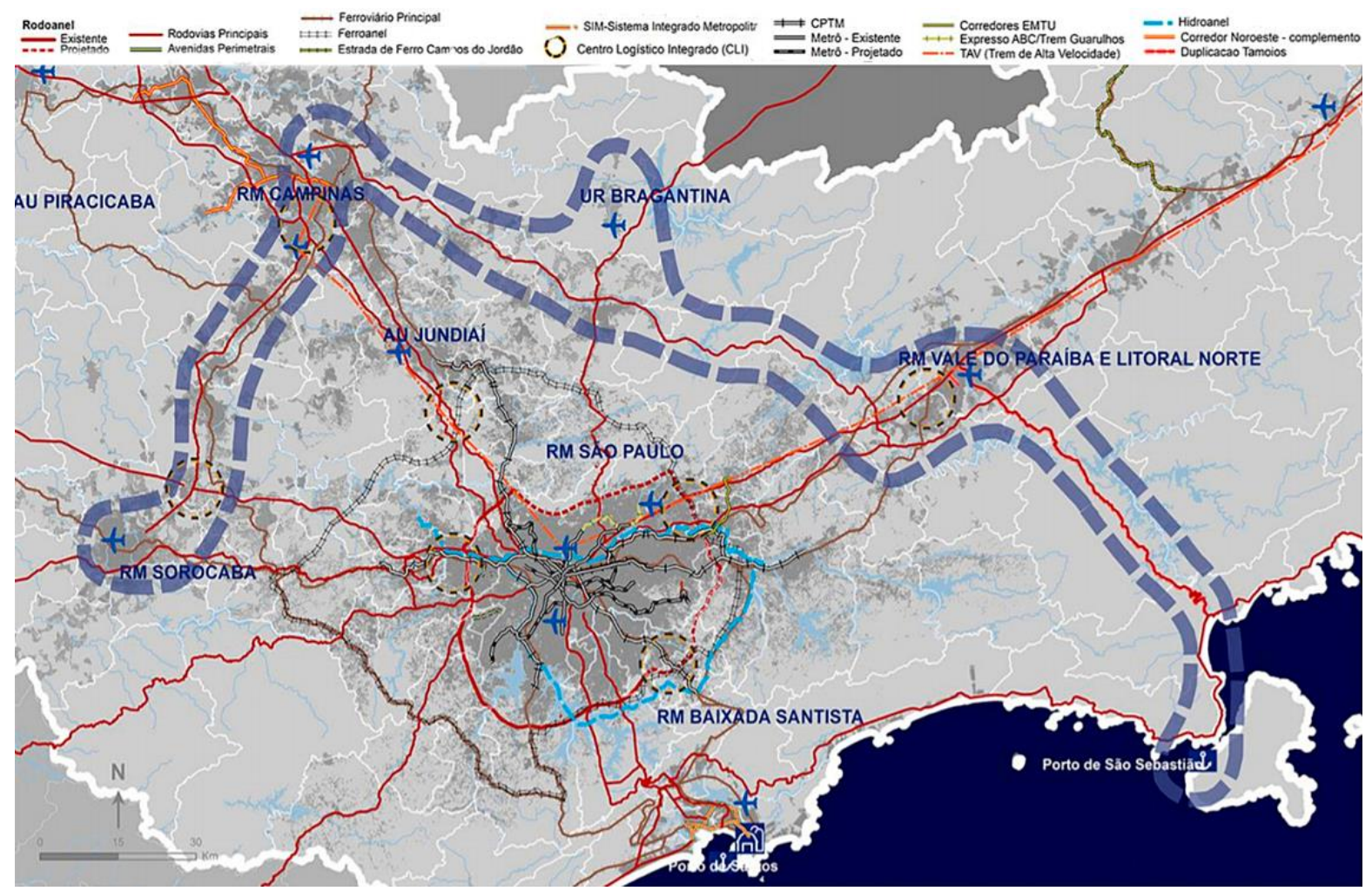

Fonte: Acréscimos dos autores sobre base da EMPLASA, 2013

Em tal situação, nos projetos do Plano de Ação da Macrometrópole Paulista, tendo como foco a análise do território da Região Metropolitana do Vale do Paraíba e Litoral Norte, percebe-se que a principal proposição é intensificar a ligação entre a capital, São Paulo, com São José dos Campos e Taubaté, as duas maiores cidades da região. Em resumo, para a RMVPLN, a Carteira de Projetos do PAM tem previsão de implantação de sistemas de transporte sobre trilhos; integração de sistemas multimodais; sistema viário; articulação e infraestrutura logística; sistema de ciência e tecnologia (C\&T); uso do solo e turismo ecológico.

Em análise mais acurada, pode-se inferir que essas regiões, aparentemente autônomas e surgidas posteriormente à metrópole paulista original, não seriam mais do que o transbordamento da pioneira, justificando assim o conceito de Macrometrópole Paulista. Contudo, a sua base é a possibilidade de desenvolvimento estritamente econômico, fato que deixa claro como o conceito de planejamento regional e o modelo de desenvolvimento estão permeados por interesses privados, 
centrados na "atração de investimentos produtivos" (NEGREIROS, SANTOS e MIRANDA, 2015).

\section{A formação e institucionalização da RMVPLN}

A Região Metropolitana do Vale do Paraíba e Litoral Norte (RMVPLN) é formada por 39 municípios distribuídos em cinco regiões de governo: São José dos Campos, Taubaté, Caraguatatuba, Guaratinguetá e Cruzeiro. Localiza-se na porção leste do estado de São Paulo, ocupando uma área de 16.268 quilômetros quadrados, correspondendo a $6,5 \%$ do território paulista. Por ser dotada de grande reserva de água e pelo fato de uma boa parcela da Mata Atlântica preservada no Brasil estar em seu território, o Vale do Paraíba é uma região diversa, em que as questões relativas ao meio ambiente desafiam os governos locais a lidar com a paradoxal relação entre o desenvolvimento simplesmente econômico e as necessidades de preservação ambiental.

O desenvolvimento histórico da região determinou grande concentração de riqueza em alguns municípios, especialmente nos que abrigam as grandes indústrias (RIBEIRO-MOREIRA; MELLO, 2010). A Refinaria Henrique Lage - REVAP da PETROBRÁS e a Empresa Brasileira de Aeronáutica S.A. (EMBRAER), além do Instituto Nacional de Pesquisas Espaciais (Inpe), o Centro Tecnológico da Aeronáutica (CTA), estão todos instalados em São José dos Campos, fato que faz desse município seu principal centro urbano. Ainda que com grande potencial turístico, principalmente histórico, existem no Vale do Paraíba cidades "adormecidas", como Bananal, Areias e São José do Barreiro, há muito isoladas, desde que as modernas opções rodoviárias, nos anos de 1940, as preteriram, deixando esses municípios ainda presos em um contexto que, em alguns aspectos, remete ao século XIX.

Cercado pela Serra da Mantiqueira e pelos contrafortes da Serra do Mar, o Vale do Paraíba é cortado pela via Presidente Dutra, que liga São Paulo ao Rio de Janeiro. Somada a essa, servem a região rodovias longitudinais e transversais, bem como o que ainda resta da antiga Estrada de Ferro Central do Brasil; além do Porto de São Sebastião e os aeroportos de São José dos Campos, Guaratinguetá e Ubatuba. Todo esse diverso sistema de circulação de pessoas e mercadorias tem muito potencial e, ao mesmo tempo, grandes problemas estruturais e desafios a serem transpostos, principalmente no que concerne à fragmentação do território.

Determinantes socioeconômicas são comprometedoras do acesso à renda e responsáveis pelo rebaixamento desta e, na RMVPLN, marcante a desigualdade no espaço intrametropolitano (TAVARES; COUTO, 2017). Nesse sentido, o movimento migratório entre os municípios da região, com o planalto perdendo indivíduos para a calha do vale, tem obedecido a uma lógica na qual os municípios 
de menor população e oportunidades de trabalho estão em processo de redução do seu número de habitantes (CUNHA, SILVA e BECCENERI, 2019).

\section{O processo de criação da Região Metropolitana do Vale}

Na medida em que o processo de desenvolvimento da região se intensificava, houve a necessidade de criação de políticas de desenvolvimento regional, com o objetivo de contribuir para a interiorização das atividades industriais no estado de São Paulo, principalmente na década de 1970. Foram implantados vários planos que previam investimentos em infraestrutura no interior do estado, principalmente em vias de circulação e acesso, para que as cidades pudessem receber as plantas industriais, resultando no fortalecimento dos polos regionais/locais do interior, sempre ligados à metrópole da capital, como uma extensão dessa (VIEIRA, 2009).

Em 1970 é criado o Consórcio de Desenvolvimento Integrado do Vale do Paraíba (CODIVAP), com o objetivo de aproximar e estimular o debate entre os municípios consorciados da região, na busca de soluções de problemas comuns. A localização do Vale do Paraíba no grande corredor industrial do país, fato que poderia vir a integrá-lo a uma megalópole, justificava a criação do consórcio (VIEIRA; SANTOS, 2012). O primeiro superintendente do CODIVAP, ainda durante o governo do general Emílio Garrastazu Médici, foi seu ex-ministro da Indústria e Comércio, Paulo Egydio Martins, que posteriormente deixou o cargo para assumir o governo paulista. Essa relação política evidencia a vinculação dos interesses locais com os nacionais e estaduais em um período de forte centralização política, administrativa e econômica, mesmo que na apresentação do relatório de caracterização da região, esse mesmo superintendente ratifique a importância do consórcio para a descentralização administrativa.

Em termos de planos elaborados pela Secretaria de Estado de Economia e Planejamento de São Paulo, conduzida na época pelo arquiteto Jorge Wilheim, destaca-se o Plano Regional do Macro-Eixo Paulista, de 1978, que teve influência de forças externas e ultrapassava os limites estritamente geográficos do Vale do Paraíba, na medida em que, pela primeira vez, era inserido o Litoral Norte ao conjunto da região de planejamento. O objetivo do plano era amenizar o problema da região metropolitana de São Paulo, com forte expansão demográfica na época. Em relação ao Vale do Paraíba, visava apresentar um diagnóstico dos aspectos socioeconômicos e ambientais da região e propor diretrizes e cenários alternativos para a elaboração de políticas para a coordenação de investimentos, ordenação espacial e planejamento territorial. No entanto, com a ruptura das políticas públicas devidas às substituições ocorridas no governo estadual, em 1979, e a consequente mudança de prioridades, o programa Macro-Eixo acabou abandonado. Sua única diretriz implantada, ainda que de modo parcial, é o Complexo Rodoviário Ayrton Senna-Carvalho Pinto. 
A primeira tentativa de se criar uma forma de planejamento institucionalizado para a região ocorre apenas em 2001, a partir da apresentação de um Projeto de Lei Complementar, na Assembleia Legislativa do Estado de São Paulo, pelo então deputado estadual Carlinhos Almeida, do Partido dos Trabalhadores. A proposta da RMVPLN foi discutida com governos municipais, partidos, universidades, sindicatos e empresários por meio de reuniões e seminários em diversas cidades. O debate promovido entre os agentes políticos da região contou, inclusive, com a presença de atores envolvidos em outras experiências de governança regional, que trouxeram exemplos e experiências nas criações de suas Regiões Metropolitanas, como os casos da Baixada Santista e Região de Campinas.

A alusão a esses processos em outras regiões do estado pode ser cotejada nas falas dos sujeitos envolvidos na formulação do projeto, como se pode ver no trecho a seguir da entrevista com Carlinhos Almeida, ex-prefeito de São José dos Campos e deputado propositor do Projeto de Lei Complementar N. 12 de 2001:

Pesquisei e vi o seguinte, a região de Campinas havia feito uma luta muito
forte pela criação da Região Metropolitana de Campinas. (...) Com a
Constituinte Federal e depois Estadual, isso foi regulamentado não tanto
com aquela visão, com uma visão um pouco diferente do que se tinha no
regime militar, de articulação regional mesmo, então, não tanto uma coisa
de cima pra baixo, mas uma visão de baixo para cima. (...) E isso permitiu
que se abrisse a discussão de outras regiões metropolitanas no nosso caso
aqui, no estado de São Paulo, e Campinas fez esse movimento e
conseguiu. Diferente de São Paulo que foi uma decisão do governo
federal de criar uma região metropolitana, foi um movimento da
sociedade e das lideranças políticas, prefeitos, deputados dali da região,
que conseguiu. (...) aí eu falei: por que nós não podemos fazer isso na
região do Vale? A partir daí nós começamos a fazer os estudos e as
conversas, levando em conta as semelhanças e as diferenças, que acho
que são até maiores do que as semelhanças, entre as duas regiões
(ALMEIDA, 2019).

A ideia em si obteve a adesão de alguns atores sociais e resistência de outros. Os apoios vieram principalmente de parte dos prefeitos, sindicatos de trabalhadores, entidades empresariais e segmentos das universidades; algumas por identificação política com o autor do projeto, outras por interesses mais próximos e outras ainda pela relação com a proposta de investir no que seria uma plataforma para execução de um plano de desenvolvimento estratégico para a região. As dissensões foram apontadas por estudiosos da temática, principalmente pela carência do chamado "fato metropolitano", já que a região caracterizava pouca densidade populacional e pontos de conurbação dispersos (LIMA, 2010).

A narrativa dos atores mostra que esse processo de construção levou à formatação de uma proposta apresentada de forma aberta, como um instrumento para forçar 
um debate qualificado, estimulado pelos propositores e articulado com os diferentes atores regionais, na direção da aprovação da RM e em afirmação do fato regional, visto principalmente nas questões ambientais; mobilidade; saúde; educação e cultura.

O governo do estado, por seu lado, apresenta a alternativa da criação de um aglomerado urbano, entre os municípios da denominada "Calha do Vale" (de Jacareí a Guaratinguetá) e três microrregiões (Mantiqueira, Litoral Norte e Vale Histórico). Muito distante da ideia inicialmente proposta, os autores do PLC consideram, conforme os depoimentos em entrevistas, essa uma forma de autodefesa encontrada pelo governo do estado para evitar a criação da RMVPLN naquele momento.

Depois de um período de efervescência dos debates sobre a criação da RMVPLN, ocorre um tempo de esvaziamento, fato que conduz ao arquivamento do PLC 12 de 2001. Essa situação provoca uma mudança de estratégia por parte do então deputado Carlinhos Almeida que, alguns anos depois, em 2007, reapresenta a proposta; dessa vez, porém, sustentada por uma frente parlamentar que, articulada em torno da aprovação do projeto, contava com vários deputados estaduais da região. Diferentemente da disposição inicial de colocar a RMVPLN em discussão com a sociedade em geral, dessa vez as investidas voltaram-se ao sentido de conciliação com o governo do estado. Para tanto, adotou-se a tática da formação de uma frente parlamentar, inclusive com deputados de partidos mais próximos ao do governador $^{2}$ (CÂNDIDO, 2010; VALE, 2012).

A questão de fundo é que a instituição da RM implica em uma transferência do poder de decisão do governador do estado para o conjunto de prefeitos da unidade de planejamento, fato considerado por Mário Covas, governador paulista entre 1995 e o início de 2001 que criou as regiões metropolitanas da Baixada Santista (1996) e de Campinas (2000). No entanto, ao contrário de seu antecessor, a política de descentralização de decisões e investimentos não seria bem vista pelo seu vice por dois mandatos e depois sucessor, a partir da metade do seu segundo mandato, Geraldo Alckmin. Assim, o próprio compromisso pela criação da RM só seria assumido bem mais tarde, em 2010, pelo governador Alberto Goldman quando, em substituição a José Serra, este se lançou em campanha pela presidência da república. Com o retorno de Geraldo Alckmin, em 2011, o compromisso seria mantido, porém, no estilo do governador empossado, esvaziado em suas atribuições, no que tange a participação efetiva dos diversos atores sociais.

De acordo com a entrevista de José Luiz Pedretti, ex-presidente da EMPLASA, ainda em 2011 foram iniciados os trabalhos naquela empresa, objetivando a criação

\footnotetext{
2 Assim, o autor do PLC N. 12 de 2001, Carlinhos Almeida, do Partido dos Trabalhadores, articulou-se com os seguintes deputados: do Partido Verde, Afonso Lobato, do Partido Progressista, Mouzart Russomano, do Partido Progressista Social, Luis Carlos Gondim, do Partido Social Cristão, Said Mourad, entre outros que aderiram posteriormente, como p. ex. o deputado do Partido Democrata Trabalhista, Aloísio Vieira.
} 
da RMVPLN. Uma publicação editada pela EMPLASA, em 2009/10, sobre o processo de regionalização paulista, destacadamente controversa dentro da empresa, segundo Pedretti, apresentava a Região do Vale do Paraíba dividida em cinco partes, dentre elas microrregiões e aglomerações. Porém, após estudos complementares, chegou-se à conclusão de que o Vale do Paraíba e o Litoral Norte deveriam ser uma unidade, uma Região Metropolitana, apesar do relevo, as regiões apresentam uma grande conexão, afirma Pedretti.

Após pouco mais de 10 anos da apresentação do PL pioneiro, a lei complementar estadual, aprovada em 2012, de número 1.166, instituiu a criação de um Conselho de Desenvolvimento e um Fundo de Desenvolvimento da RMVPLN, tendo ambos sido instituídos, um em 2012 e o outro em 2013, posteriormente, por meio do Decreto N. 61.256, de 08 de maio de 2015, ocorreu a aprovação do Regulamento da Agência Metropolitana do Vale do Paraíba e Litoral Norte (AGEMVALE), criada pela Lei Complementar N. 1.258, de 12 de janeiro de 2015.

Verifica-se, contudo, que a RMVPLN pouco avançou desde sua criação. De certo modo a criação da nova região metropolitana parece ter sido a concretização de um processo meramente burocrático que aglutinasse prefeitos alinhados ao executivo estadual. Sintoma dessa postura se reflete em sua subdivisão regional que, ao contrário de ações anteriores que evidenciavam aspectos geoecológicos, socioeconômicos e culturais, conservou a divisão política e burocrática das subregiões administrativas, sem considerar as características específicas de cada uma dessas unidades.

Diante de tamanha fragmentação regional, apesar de necessitar que os municípios se articulem em torno da integração e do planejamento regional, o que mais tem para ser observado recentemente, do ponto de vista político, tem sido a insistência do governo do estado, que tem se esforçado para eleger prefeitos de sua base aliada, tanto como presidentes do CODIVAP, bem como do Conselho de Desenvolvimento da RMVPLN, reafirmando um claro costume centralizador que vem perdurando atualmente. Do ponto de vista político-administrativo, é temerária a recente extinção da EMPLASA, em 2018, fato potencialmente causador de um rompimento no quadro técnico e, por conseguinte, na capacidade do poder público estadual de construir planos em longo prazo.

Ademais, o governo sustenta ter investido, desde $2011^{3}$, cerca de 11 bilhões de reais na RMVPLN, entre eles, na execução de projetos como o prolongamento da Rodovia Carvalho Pinto, a modernização da Rodovia SP-062 e da Rodovia dos Tropeiros. Além das realizações acima, o governo estadual relacionou: a construção do eixo viário no contorno de Caraguatatuba; a participação no asfaltamento da

\footnotetext{
${ }^{3}$ Fonte: Governo do estado de São Paulo:

http://www.assuntosmetropolitanos.sp.gov.br/UnidadesRegionais/RMVPLN. Acesso em 14 de junho de 2019; https://www.youtube.com/user/governosp/. Acesso em 14 de junho de 2019.
} 
Estrada Real (Cunha-Paraty), em parceria com o estado do Rio de Janeiro; o restauro do patrimônio histórico de São Luís do Paraitinga; construção de novas faculdades de tecnologia, escolas, creches, dos hospitais regionais de Taubaté e de São José dos Campos e de Ambulatórios Médicos de Especialidades (AMEs); e investimentos em saneamento urbano, abastecimento de água.

Entretanto, nenhuma dessas intervenções reflete a existência da RMVPLN como potencial instrumento de governança integrativa e planejamento regional.

No início de 2017 foi publicado pelo então subsecretário de Assuntos Metropolitanos um artigo no jornal $O V$ ale $e^{4}$ em que é levantada a questão da participação dos prefeitos municipais e da sociedade civil na elaboração do Plano Diretor Urbano Integrado. Ocorrida em agosto do mesmo ano, a $17^{\mathrm{a}}$ reunião ordinária do Conselho de Desenvolvimento da RMVPLN teve registrado em ata ${ }^{5}$ a intenção de aportar recursos para a elaboração do PDUI e, recentemente, no início de junho de 2018, ocorreu a $18^{a}$ reunião do Conselho de Desenvolvimento da RMVPLN, na qual foi eleito o novo presidente do Conselho. $\mathrm{Na}$ ocasião, foi noticiada a intenção do Conselho de pautar o PDUI nas próximas reuniões ${ }^{6}$. No ano de 2018, foi feita uma minuta do Termo de Referência e o Guia Metodológico para a contratação de empresa para a realização do PDUI, sem, no entanto, previsão orçamentária ou efetivação da gestão do Fundo Vale, de onde viriam os recursos, ou seja, está configurado um impasse para sua efetivação.

Salta aos olhos o fato de a MMP ter criado a carteira de projetos do PAM com previsão de investimentos para os anos entre 2020 e 2040, sem considerar a criação do PDUI. Ao analisar a carteira de projetos do PAM (EMPLASA, 2014b, p. 114), observa-se que os chamados "resultados por projetos estratégicos", dos 13 projetos destinados ao desenvolvimento do vetor "Vale do Paraíba", 10 são de infraestrutura viária, ferroviária, aeroviária ou portuária enquanto os outros três pretendem determinar a orientação para uso e ocupação do solo no setor; adensamento do Parque Tecnológico de São José dos Campos e promoção do turismo sustentável no setor.

Com o discurso de integração e adensamento da região, com a MMP foram reduzidos significativamente os investimentos em projetos de mobilidade, transporte e infraestrutura, notadamente com ênfase na circulação de mercadorias (EMPLASA, 2014b). Ainda que sem considerar os investimentos necessários para

\footnotetext{
4 Subsecretaria de Assuntos Metropolitanos: www.assuntosmetropolitanos.sp.gov.br/noticias/artigosassinados. Acesso em: 14 jun. 2019.

${ }^{5}$ Conforme publicado no site da Agemvale: http://www.suaboxonline.com/agemvale-site/atas. Acesso em: 14 jun. 2019.

${ }^{6}$ Conforme noticiado pelo jornal Meon: Prefeito de Paraibuna assume a presidência do Conselho da RMVale. Jornal Meon, 7 jun. 2018. Disponível em: http://bit.ly/2Jz8A7z. Acesso em: 5 jan. 2021.
} 
as estradas vicinais, fundamentais para a interligação dos pequenos municípios e as propostas de investimentos nas áreas de planalto.

\section{Considerações finais}

A concepção teórico conceitual das regiões enquanto unidades territoriais, no contexto do processo de metropolização, ajudam a compreender as justificativas da criação da escala macrometropolitana no estado de São Paulo. Ainda que justificada, é preciso destacar que a criação de uma nova unidade de planejamento não é, por si só, capaz de dirimir as questões institucionais envolvidas no processo de reescalonamento do território e de concepção da política urbana brasileira, permanecendo o dilema.

As políticas urbanas se mostram tendencialmente atuantes para a manutenção de um status de produtividade elevada do capital dominante, entrando em consonância com necessidades e determinações dos planos regionais metropolitanos. A produção do espaço regional se dispersa, conectada com a escala estadual, quiçá internacional, em eixos continentais, já que é sabida a natureza dos fluxos econômicos dispostos no território da MMP, de importância estratégica nacional e global.

Com a leitura e análises do PAM identificou-se a presença de uma política de planejamento que promove o adensamento da metropolização da região, de forma a reforçar essas áreas em relação às demais do país por via dos eixos existentes, e promover a intensificação das atividades econômicas por eles viabilizadas, com o objetivo do aumento dos fluxos entre as unidades produtoras e os canais de circulação de mercadorias, colocando nitidamente a via de desenvolvimento dirigida aos vetores dominantes, quais sejam, transportes e mobilidade.

Assim como aconteceu com o plano regional de 1978, a agenda proposta pelo PAM faz pouca menção a projetos de governança e, na prática, não envolve os atores políticos estatais e não estatais no processo de tomada de decisão de forma efetiva. Além disso, a estratégia proposta se vincula centralmente ao viés de desenvolvimento econômico. Ainda que a governança da MMP seja importante em sua dimensão escalar, é imprescindível atentar aos desafios postos para o modelo de desenvolvimento econômico na era neoliberal e pós-keynesiana, essencialmente gerador de crises socioambientais.

Nesse contexto, a criação da Região Metropolitana do Vale do Paraíba e Litoral Norte e a sua institucionalização, nos moldes aqui observados, apontam como esse arranjo de governança se encontra num vazio, no caso estudado, distante da ideia de planejamento existente na proposta original, em 2001, então voltada para as necessidades regionais. O conhecimento desses eventos leva a crer que o andamento das ações estatais na região pode agravar ainda mais as disparidades, tendo em vista 
o quadro apontado historicamente de desenvolvimento, em que permaneceram mais frágeis algumas localidades, diferentemente de outras, já consolidadas. Além disso, em se mantendo a forma centralizada de planejamento e tomada de decisões, permanecem as perspectivas de esvaziamento institucional da Região Metropolitana, ainda passível de consolidação.

Fica nítida a presença de um arranjo institucional sobreposto na política de escalas, por um lado, focado no sentido da integração entre as demais regiões metropolitanas que integram a MMP. Contudo, nem as leis estadual e federal do Estatuto da Metrópole, dão conta de sanar potenciais demandas, já que elas são levadas a cabo com base nos interesses privados, gerando uma contraditória forma de planejamento e governança. A difícil constatação dessa lógica, infelizmente, é a prática mais comum, a da promoção de um "planejamento" a posteriori, que tenta remediar o mal já feito — um antiplanejamento, baseado na agenda permanentemente omitida de projetos do governo de ocasião.

Para contribuir na direção da formulação de alternativas às políticas de planejamento e governança metropolitana predominantes, resta dizer que cabe o desafio à academia de fazer a crítica desse processo dentro dos marcos teóricos estudados, de tal modo que contribua provoque a reflexão e interesse dos atores envolvidos na transformação da realidade.

\section{Fonte de Financiamento}

Coordenação de Aperfeiçoamento de Pessoal de Nível Superior (CAPES).

\section{Referências}

BRANDÃO, C. A. Descentralização enquanto modo de ordenamento espacial do poder e de reescalonamento territorial do Estado: trajetória e desafios para o Brasil. In: DALLABRIDA, V. R. (Org.) Governança territorial e desenvolvimento: descentralização político-administrativa, estruturas subnacionais de gestão do desenvolvimento e capacidades estatais. Rio de Janeiro: Garamond, p. 115-135, 2010.

BRENNER, N. Espaços da urbanização: o urbano a partir da teoria crítica. Rio de Janeiro. Ed. Letra Capital; Observatório das Metrópoles, 2018.

BRENNER, N. A globalização como reterritorialização: o reescalonamento da governança urbana na União Europeia. Cadernos Metrópole, vol. 12, n. 24, p. 535-564, 2010. 
BRENNER, N. New state spaces: urban governance and the rescaling of statehood. New York: Oxford University Press, 2004.

CÂNDIDO, L. R. Informativo da Frente Parlamentar em apoio aos municípios do Vale do Paraíba, Litoral Norte e Serra da Mantiqueira. São Paulo: Assembleia Legislativa do Estado de São Paulo, jun. 2010.

CASTRO, H. R.; SANTOS Jr., W. R. A expansão da macrometrópole e a criação de novas RMs: um novo rumo para a metropolização institucional no estado de São Paulo? Cadernos Metrópole, vol. 19, n. 40, p. 703-720, 2017.

COX, K. The problem of metropolitan governance and the politics of scale. Regional Studies, vol. 44, n. 2, p. 215-227, 2010.

CUNHA, J. M.; SILVA, K. A. A. S.; BECCENERI, L. B. (Org.) Vale do Paraíba e Litoral Norte: diversidades socioespaciais. Campinas: Librum Editora, 2019.

EMPLASA. Plano regional do macro-eixo paulista. São Paulo: Empresa Paulista de Desenvolvimento Metropolitano; Secretaria de Economia e Planejamento/Coordenadoria de Ação Regional, 1978.

EMPLASA. Plano de ação da Macrometrópole Paulista, 2013-2040: política de desenvolvimento da macrometrópole (vol. 1). São Paulo: Empresa Paulista de Desenvolvimento Metropolitano, 2014a.

EMPLASA. Plano de Ação da Macrometrópole Paulista, 2013-2040: coleção carteira de projetos do PAM. (vol. 2). São Paulo: Empresa Paulista de Desenvolvimento Metropolitano, 2014b.

EMPLASA; SEADE. O estado dos municípios. São Paulo: Empresa Paulista de Desenvolvimento Metropolitano; Fundação Sistema Estadual de Análise de Dados, 2014.

FAORO, R. Os donos do poder: a formação do patronato brasileiro. 3 ed. São Paulo: Globo, 2001.

FERNANDES, A. C. Da reestruturação corporativa à competição entre cidades: lições urbanas sobre os ajustes de interesses globais e locais no capitalismo contemporâneo. Espaço e Debates, N. 41, p. 26-45, 2001.

FERREIRA, J. S. W. São Paulo, o mito da cidade-global: ideologia e mercado na produção da cidade. Anais do VI Seminario Internacional de Desarrollo Urbano (Unidad Temática: Desarrollo Urbano de la Red de Mercociudades; 
Tema: La ciudad global: existe en el Mercosul? Gestion urbana local en el tiempo mundial). Buenos Aires, 3-4 jul. 2003 [Editado pela P. M. Rio Claro, out. 2003].

FIORI, J. L. O federalismo diante do desafio da globalização. In: AFONSO, R. B. A.; SILVA, P. L. B. (Org.) A federação em perspectiva: ensaios selecionados. São Paulo: FUNDAP, 1995.

FREY, K. Governança urbana e participação pública. Revista de Administração Contemporânea, n. 1, p. 136-150, 2007.

GOMES, C.; RESCHILIAN, P. R.; UEHARA, A. Perspectivas do planejamento regional do Vale do Paraíba e litoral norte: marcos históricos e a institucionalização da região metropolitana no Plano de Ação da Macrometrópole Paulista. Urbe. Revista Brasileira de Gestão Urbana, vol. 10, n. 1, p. 154-171, 2018.

HARVEY, D. Condição pós-moderna: uma pesquisa sobre as origens da mudança cultural. 25 ed. São Paulo: Loyola, 2014.

HARVEY, D. A produção capitalista do espaço. São Paulo: Annablume, 2005.

Jornal O Vale. Informativo sobre a Região Metropolitana do Vale do Paraíba e Litoral Norte. Jornal $\boldsymbol{O}$ Vale, 2012.

Jornal MEON. Prefeito de Paraibuna assume a presidência do Conselho da RMVale. Jornal MEON, 7 jun. 2018. Disponível em: http://bit.ly/2Jz8A7z. Acesso em: 9 abr. 2020.

\section{LEITÃO, K. O. A dimensão territorial do Programa de Aceleração do}

Crescimento: um estudo sobre o PAC no estado do Pará e o lugar que ele reserva à Amazônia no desenvolvimento do país. São Paulo. 2009. Tese (Doutorado em Arquitetura e Urbanismo) - FAU/USP, 2009.

LENCIONI, S. Metrópole, metropolização e regionalização. São Paulo: Editora Consequência, 2017.

LENCIONI, S. Urbanização difusa e constituição de megarregiões: o caso de São Paulo-Rio de Janeiro. e-metrópolis, vol. 6, n. 22, p. 6-15, 2015.

LENCIONI, S. O processo de metropolização do espaço: uma nova maneira de falar da relação entre metropolização e regionalização. In: SCHIFFER, Sueli R.

(Org) Globalização e estrutura urbana. São Paulo: HUCITEC, 2004. 
LEONEL, A. L.; ZIONI, S.; MOMM, S. Macrometrópole Paulista: apontamentos sobre uma nova unidade de planejamento. Anais do XVIII ENANPUR:

Encontro Nacional de Pós-Graduação em Planejamento Urbano. Natal, 27-31 mai. 2019.

LIMA, A. Região metropolitana: Sim, nós podemos!". Revista Vida Urbana, vol. 2 , n 9, p. 12-17, ago. 2010.

LIPIETZ, A. Le capital et son espace. Paris: Maspero, 1988.

MONTE-MÓR, R. L. O que é o urbano no mundo contemporâneo. Revista Paranaense de Desenvolvimento, n. 111, p. 9-18, jul./dez. 2006.

MOURA, R.; HOSHINO, T. A. P. Estatuto da metrópole: enfim, aprovado! Mas o que oferece à metropolização brasileira? Curitiba: Observatório das Metrópoles/INCT/CNPq; Fund. Escola do Ministério Público do Paraná, s. d.

NEGREIROS, R.; SANTOS, S. M. M.; MIRANDA, Z. A. I. Nova escala de planejamento, investimento e governança na Macrometrópole Paulista. Revista Iberoamericana de Urbanismo. Vol. 7, n. 12, p. 121-135, 2015.

OLIVEIRA, F. Crítica à razão dualista/o ornitorrinco. São Paulo: Boitempo, 2003.

RIBEIRO-MOREIRA, P.; MELLO, L. F. Desenvolvimento econômico, população e impactos ambientais: mudanças contemporâneas no extremo leste paulista. Anais do XVII Encontro Nacional de Estudos Populacionais (ABEP). Caxambu, 20-24 set. 2010.

SANTOS, M. A urbanização brasileira. São Paulo: Edusp, 2005.

TAVARES, J. C. Formação da macrometrópole no Brasil: construção teórica e conceitual de uma região de planejamento. Eure, vol. 44, n. 133, p. 115-134, 2018.

TAVARES, J. C. Eixos, novo paradigma do planejamento regional? Cadernos Metrópole, vol. 18, n. 37, p. 671-695, 2016.

TAVARES, S. R.; COUTO, M. F. R. O Índice de vulnerabilidade social na Região Metropolitana do Vale Do Paraíba e Litoral Norte. Territórios, redes e desenvolvimento regional: perspectivas e desafios. Santa Cruz do Sul, 13-15 set. 2017.

VALE. Informativo sobre a Região Metropolitana do Vale. 2012. 
VIEIRA, E. T.; SANTOS, M. J. Industrialização e desenvolvimento regional: política do CODIVAP no Vale do Paraíba na década de 1970. Desenvolvimento Regional em Debate, vol. 2, n. 2, p. 161-181, 2012.

\section{VIEIRA, E. T. Industrialização e políticas de desenvolvimento regional: o} Vale do Paraíba paulista na segunda metade do século XX. São Paulo. 2009. Tese (Doutorado em História Econômica) - Universidade de São Paulo, 2009.

Data de submissão: Data de submissão: 09/04/2020

Data de aprovação: 08/01/2021

Revisão: Daniela Matthes (português), Anderson de Miranda Gomes (inglês) e Yanet María Reimondo Barrios (espanhol).

\section{Rosa Scaquetti}

Programa de Pós-Graduação em Planejamento Urbano e Regional / Universidade do Vale do Paraíba

Avenida Shishima Hifumi, 2911 - Urbanova

12244-000 São José dos Campos/SP, Brasil

Orcid: http://orcid.org/0000-0003-2677-738X

E-mail: rosamariascaquetti@gmail.com

Pedro Ribeiro-Moreira

Programa de Pós-Graduação em Planejamento Urbano e Regional / Universidade do Vale do Paraíba

Avenida Shishima Hifumi, 2911 - Urbanova

12244-000 São José dos Campos/SP, Brasil

Orcid: http://orcid.org/0000-0002-0659-5549

E-mail: pedro.ribeiro@univap.br 
Rosa Scaquetti e Pedro Ribeiro-Moreira

174| Revista Brasileira de Desenvolvimento Regional, Blumenau, 9 (1), P.149-174, 2021 